\title{
Producción de blastosporas de Simplicillium lanosoniveum en medios de cultivo líquidos
}

\section{Production of blastospores of Simplicillium lanosoniveum in liquid culture media}

\author{
Gerardo García-Nevárez ${ }^{1}$, Eduardo Hidalgo-Jaminson ${ }^{2}$, Rodolfo Velásquez-Valle ${ }^{1}$ \\ ${ }^{1}$ Instituto Nacional de Investigaciones Forestales Agrícolas y Pecuarias, Campo Experimental Delicias. Carretera Delicias-Rosales km \\ 2.5, Delicias, C.P. 33000, Chihuahua, México. \\ ${ }^{2}$ Centre for Agriculture and Bioscience International, Turrialba, C.P. 30501, Cartago, Costa Rica.
}

\section{RESUMEN}

Antecedentes: Los hongos del género Simplicillium son enemigos naturales de la roya del café, Hemileia vastatrix. La producción de altas concentraciones de propágulos del micoparásito es fundamental para el manejo biorracional del patógeno.

Objetivos: Evaluar la producción de blastosporas de Simplicillium lanosoniveum in vitro.

Métodos: Se evaluó la producción de blastosporas de S. lanosoniveum (SL) en cuatro medios de cultivo líquidos con diferentes fuentes de carbono y nitrógeno: medio base (MB), medio Jackson (MJ), medio Bayfolan-Soya (BS) y medio

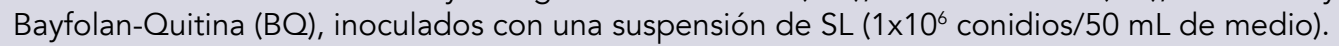

Resultados y conclusiones: Los medios BQ y BS registraron la mayor producción de blastosporas 14 días después de la inoculación $\left(B Q=1.2 \times 10^{8}\right.$ y $\left.B S=4.8 \times 10^{7}\right)$. Estos resultados demuestran que es factible su uso para la reproducción de $S$. lanosoniveum.

Palabras clave: fermentación líquida, micoparásitos, propágulos

\section{ABSTRACT}

Background: Fungi of Simplicillium genus are natural enemies of the coffee rust, Hemileia vaxtatrix. The production of high concentrations of mycoparasite propagules is essential for the biorational management of the pathogen.

Objectives: To evaluate the production of blastospores of Simplicillium lanosoniveum in vitro.

Methods: The production of blastospores of $S$. lanosoniveum (SL) was evaluated in four liquid culture media with different sources of carbon and nitrogen: base medium (MB), Jackson medium (MJ), Bayfolan-Soy medium (BS) and Bayfolan-Chitin medium (BQ), inoculated with a suspension of SL ( $1 \times 10^{6}$ conidia / $50 \mathrm{~mL}$ of medium).

Results and conclusions: The culture media $\mathrm{BS}$ and $\mathrm{BQ}$ registered the highest blastospore production 14 days after inoculation $\left(B Q=1.2 \times 10^{8}\right.$ and $\left.B S=4.8 \times 10^{7}\right)$. These results demonstrate that their use is factible to reproduce $S$. lanosoniveum.

Keywords: liquid fermentation, mycoparasites, propagules

El empleo de hongos como agentes de control biológico depende, parcialmente, de la producción de estructuras infectivas de manera económica (Latifian et al. 2013). Actualmente, la reproducción de hongos benéficos (HB) se puede realizar de manera artesanal, semi-industrial y/o industrial por compañías de biopla- guicidas; la diferencia principal entre estos sistemas radica en los volúmenes de producción (Monzón 2001). Las técnicas de reproducción masiva de HB incluyen la fermentación bifásica, inicialmente se producen propágulos en medio líquido y posteriormente el inóculo obtenido se siembra sobre sustratos sólidos para obtener

\section{ARTICLE HISTORY}

Received: 26 April 2021 / Accepted: 24 November 2021

Published on line: 26 November 2021

\section{CORRESPONDING AUTHOR}

\u Rodolfo Velásquez-Valle, velasquez.rodolfo@inifap.gob.mx ORCID 0000-0003-0820-8837 
conidios (Sahayaraj y Raja 2008). Bajo estas condiciones, el medio de Saboraud, dextrosa y agar (SDA) es el más recomendado para la producción de conidios de Lecanicilium lecanii, suplementado con polvo de camarón, con un rendimiento superior a $5 \times 10^{9}$ conidios/ mL (Reyes-Hernández et al. 2014).

Los hongos del género Simplicillium W. Gams \& Zare, son los principales enemigos naturales de Hemileia vastatrix Berk. \& Broome en Costa Rica (García-Nevárez 2018). En Centroamérica, en 2012-2013, la roya causó pérdidas superiores a US $\$ 499$ millones (Promecafé/IICA 2013). Actualmente, el manejo de la roya en Costa Rica se basa en fungicidas cúpricos de contacto; desafortunadamente el cobre debe estar presente sobre las hojas previamente a la infección y se puede acumular en la materia orgánica del suelo en niveles fitotóxicos (Arneson 2000). El biocontrol de H. vastatrix puede ser factible y ambientalmente seguro, por esto, desarrollar técnicas de producción de micoparásitos como S. lanosoniveum es clave para el manejo biorracional del patógeno. El objetivo de esta investigación fue evaluar medios de cultivo líquidos para la obtención de altas concentraciones de blastosporas de la especie S. lanosoniveum (SL).

La cepa de SL utilizada fue aislada de pústulas de $H$. vastatrix sobre Coffea arabica, variedad Caturra, en Turrialba, Costa Rica y codificada como EC (número de referencia de las secuencias similares en $\mathrm{NBCl}$ : MG807436.1) y se conserva en el Centro Agronómico Tropical de Investigación y Enseñanza (CATIE).

La cepa SL fue inoculada en el medio de cultivo de Papa Dextrosa Agar (PDA) para generar el inóculo inicial. Posteriormente, se evaluó la producción de blastosporas de SL utilizando los medios líquidos Jackson $(\mathrm{MJ})$, medio base (MB), medio Bayfolan-Soya (BS) y medio Bayfolan-Quitina (BQ) (Tabla 1). Los matraces con los diferentes medios se inocularon con una suspensión de SL ( $1 \times 10^{6}$ conidios $/ 50 \mathrm{~mL}$ de medio). Los matraces inoculados fueron colocados aleatoriamente sobre un agitador orbital (VWR Scientific Products, USA) a 150 rpm. La concentración de blastosporas se contó cada 24 h después de la inoculación.

Se utilizó un diseño experimental completamente al azar con cinco repeticiones; cada muestra consistió en un matraz de $125 \mathrm{~mL}$ de capacidad con $50 \mathrm{~mL}$ de medio. El análisis del número de blastosporas se realizó mediante el paquete estadístico Infostat (Di Rienzo et al. 2016), realizando un análisis de conglomerados
Tabla 1. Composición de los medios líquidos evaluados en la producción de blastosporas de Simplicillium lanosoniveum

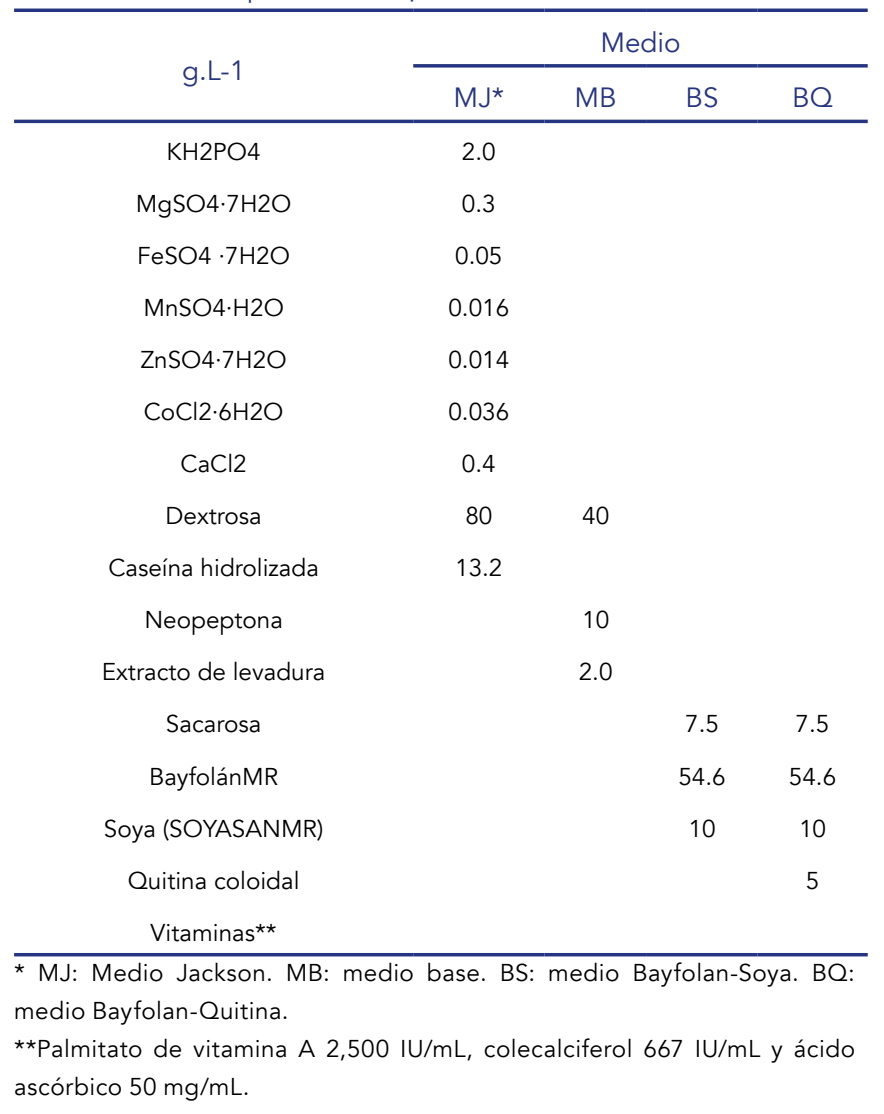

para ajustar el mejor modelo. La separación de medias fue mediante la prueba Di Rienzo et al. (2002) (DGC=0.05).

La mayor producción de blastosporas se produjo en los medios de $\mathrm{BO}$ y $\mathrm{BS}$, con picos máximos a los 14 días de incubación (DDI), respectivamente. Con menor producción, en el medio de MJ se registró el valor máximo a los $9 \mathrm{DDI}$, mientras que en $\mathrm{MB}$ se registraron los valores más bajos, alcanzando su pico máximo a los 5 DDI.

La producción de blastosporas en los medios MB y MJ declinó después del pico de producción, mientras que en las muestras de $\mathrm{BS}$ y $\mathrm{BO}$ se mantuvo estable hasta los 19 DDI. Los valores máximos de blastosporas para ambos medios cuantificados a los 14 DDI fueron de $1.2 \times 10^{8}$ blastosporas $/ \mathrm{mL}$ para $\mathrm{BO}$ y de $4.8 \times 10^{7}$ para BS (Figura 1).

Cuando el hongo cultivado en MB y MJ alcanzó su máxima producción de propágulos, cinco y ocho DDI, en las condiciones de BS y $\mathrm{BO}$ se produjeron 100 veces más blastosporas que MB y 10 veces más que $\mathrm{MJ}$. 




Figura 1. Producción de blastosporas de Simplicillium lanosoniveum en diferentes medios de cultivo.

MJ: medio Jackson. MB: medio base. BS: bayfolan soya. BQ: bayfolan quitina.



Figura 2. Blastosporas, crecimientos cilíndricos y formación de cuerpos hifales de Simplicillium lanosoniveum. Aumento 20X. 
La presencia de cuerpos hifales de SL (Figura 2) observados en MB, posiblemente retardó la producción de blastosporas que había iniciado el primer DDI, adelantándose al resto de los medios de cultivo que iniciaron la producción un día después que MB.

El número de blastosporas disminuyó a los 6 y 10 DDI en $\mathrm{MB}$ y $\mathrm{MJ}$, respectivamente. Una fase estacionaria en la producción de blastosporas se observó entre 4-7 y 8-9 DDI para MB y MJ, respectivamente. En BS y BO dicha fase se extendió desde 14 hasta 19 DDI. La adición de quitina coloidal a $\mathrm{BO}$ mejoró la producción de blastosporas; un fenómeno similar fue observado con L. lecanii y la adición de fuentes de quitina (Reyes-Hernández et al. 2014).

En general, SL cultivado en BS y BO presentó los mejores resultados en la producción de blastosporas. Estos medios presentan la ventaja de incluir fuentes de carbono y nitrógeno de amplia disponibilidad (sacarosa y el fertilizante Bayfolan®). Los medios MS y MJ tuvieron una menor producción de dichos propágulos.

Además, la producción de altas concentraciones de blastosporas de $S$. lanosoniveum en los medios de cultivo $\mathrm{BS}$ y $\mathrm{BQ}$ se mantuvo durante $19 \mathrm{DDI}$.

\section{LITERATURA CITADA}

Arneson PA. 2000. Coffee rust. The Plant Health Instructor. https:// doi.org/10.1094/PHI-I-2000-0718-02 https://www.apsnet. org/edcenter/disandpath/fungalbasidio/pdlessons/Pages/CoffeeRust.aspx
Di Rienzo JA, Guzmán AW, Casanoves F. 2002. A multiple-comparisons method base on the distribution of the root node distance of a binary tree. Journal of Agricultural, Biological and Environmental Statistics 7, 129-142.

Di Rienzo JA, Casanoves F, Balzarini MG, Gonzalez L, Tablada M, Robledo CW. 2016. InfoStat versión 2016. Grupo InfoStat, FCA, Universidad Nacional de Córdoba, Argentina.

García-Nevárez G. 2018. Evaluación de la calidad y métodos de producción de bioplaguicidas para el manejo de Hemileia vastatrix en plantaciones de café. Centro Agronómico Tropical de Investigación y Enseñanza. Tesis de doctorado. Turrialba, Costa Rica.

Latifian M, Rad B, Amani M, Rahkhodaei E. 2013. Mass production of entomopathogenic fungi Beauveria bassiana (Balsamo) by using agricultural products based on liquid - solid diphasic method for date palm pest control. International Journal of Agriculture and Crop Sciences 5, 2337-2341.

Monzón A. 2001. Producción, uso y control de calidad de hongos entomopatógenos en Nicaragua. Manejo Integrado de Plagas 63, 95-103.

Promecafé/IICA (Programa Cooperativo Regional para el Desarrollo Tecnológico y la Modernización de la Caficultura; Instituto Interamericano de Cooperación para la Agricultura). 2013. La crisis del café en Mesoamérica. Causas y respuestas apropiadas. http://promecafe.net/documents/Publicaciones/la\%20 roya\%20en\%20centroamerica.pdf

Reyes-Hernández JE, Alatorre-Rosas R, Shirai-Matsumoto K, Vaquera-Huerta H, Virgen-Calleros G, Medina-Urrutia V, Loera-Corral O. 2014. Components of liquid media on the production of high spore concentrations of Lecanicillium lecanii (Zimm.) Gams and Zare. Journal of Agricultural Science and Technology 4, 767-779.

Sahayaraj K, Raja SK. 2008. Mass production of entomopathogenic fungi using agricultural products and by products. African Journal of Biotechnology 7, 1907-1910. 